\title{
OS DESAFIOS DO LIVRO DIGITAL INTERATIVO PARA CRIANÇAS: UM OLHAR SOBRE A MATERIALIDADE E A EVANESCÊNCIA
}

\section{THE CHALLENGES OF INTERACTIVE DIGITAL BOOKS FOR CHILDREN: A GLANCE AT MATERIALITY AND EVANESCENCE}

Jaqueline Conte ${ }^{1}$

\begin{abstract}
Resumo: A transitoriedade do livro digital interativo para a infância, sobretudo dos produzidos para dispositivos móveis, e os desafios dessa nova materialidade literária são o foco deste artigo, que traz algumas das reflexões presentes na dissertação de Mestrado da autora. Em tela, um conceito para a materialidade, a multiplicidade de expertises envolvidas nas produções, dependência de grandes players do mercado, evanescência das obras, acesso pelos leitores e novo modelo de negócio voltado às escolas.
\end{abstract}

\begin{abstract}
The transience of the interactive digital book for children, especially those produced for mobile devices, and the challenges of this new literary materiality are the focus of this article, which brings some of the reflections present in the author's Masters dissertation. On screen, a concept for materiality, the multiplicity of expertise involved in the productions, dependence on major market players, evanescence of works, access by readers and a new business model aimed at schools.
\end{abstract}

Palavras-chave: Livros digitais interativos para crianças; App-books; Materialidade da literatura infantil; Prêmio Jabuti; Bibliotecas digitais

Keywords: Interactive digital books for children; App-books; Materialityof literature; Jabuti Award; Digital libraries

Os livros digitais interativos para crianças, que exploram as múltiplas possibilidades do meio digital, tais como interatividade, multilinguagem e hipermidialidade, ainda são uma alternativa pouco explorada pelo mercado do livro no Brasil e pouco utilizada por leitores, escolas e mediadores de leitura. Essa nova materialidade da literatura para a infância, sobretudo quando se trata dos livros produzidos para dispositivos móveis, traz consigo muitos desafios, entre eles o custo de produção, a evanescência das obras, a dependência de políticas estabelecidas por terceiros (grandes corporações que fazem a ponte entre produtor e consumidor/leitor), a dificuldade de acesso por parte do público e o próprio entendimento do que seja essa materialidade.A transitoriedade do livro digital para a infância e o desafio dessa nova materialidade são o cerne deste artigo, que traz de maneira sucinta algumas das reflexões do trabalho que defendemos em 2019, como requisito parcial para a obtenção

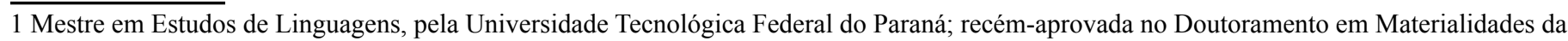
Literatura, na Universidade de Coimbra. 
do título de Mestre em Estudos de Linguagens, pela Universidade Tecnológica Federal do Paraná . A referida dissertação propunha oferecer um recorte histórico de um fenômeno então e, ainda hoje, em desenvolvimento no país - o livro digital interativo para crianças, bem como problematizar questões nevrálgicas relacionadas ao tema, como diferentes formatos disponíveis, caráter multiautoral, materialidade do livro digital, evanescência das obras, demanda e mercado dessas produções interativas para crianças.

Os estudos que levaram ao trabalho supracitado partiram de pesquisa exploratória e fundamentação teórica alicerçada, sobretudo, em nomes como Katherine N. Hayles, Jorge Luiz Antonio, Deglaucy Jorge Teixeira, Alamir Aquino Corrêa, Edgar Roberto Kirchof e Ana Elisa Ribeiro. Foram utilizados diferentes métodos e ferramentas de pesquisa, incluindo apreciações de caráter imanente de 13 objetos: os livros vencedores de primeiro, segundo e terceiro lugares na categoria Infantil Digital do Prêmio Jabuti, a principal premiação do mercado livreiro do Brasil. Foram apresentados todos os vencedores de 2015 a 2017³, anos em que a categoria permaneceu no Prêmio, e mapeadas as características e recursos técnicos por eles utilizados (áudio - sons, trilhas sonoras, narrações; animações; jogos e atividades lúdicas;vídeos; interações por gravidade; possibilidade de gravação de áudio; sinalizações de ações a serem feitas; links externos; atualizações; tamanho do livro e número de cenas; registro no ISBN; preço de venda; existência ou não de versão impressa da obra; relação entre preços das duas versões; entre outros dados), com análise comparativa. Também foram apresentados dados quantitativos de pesquisas já disponíveis sobre crescimento no consumo de dispositivos eletrônicos móveis no Brasil, leitura na internet e consumo de livros eletrônicos. Foram realizadas entrevistas com produtores digitais (editoras tradicionais, editoras exclusivamente digitais, bibliotecas digitais), presenciais, em profundidade, e também com questões abertas, enviadas por e-mail. Foi aplicada, ainda, pesquisa com formulário on-line semiestruturado, direcionada a autores de literatura infantil e juvenil (119 escritores e ilustradores participaram), para aferir o conhecimento e o interesse desse público em relação ao consumo e à produção de livros digitais. Essas, portanto, foram algumas das ferramentas metodológicas utilizadas nos estudos.

Neste artigo, deixaremos em segundo plano a seção de caráter historiográfico da pesquisa que, além de apresentar e comparar os livros premiados, aborda o contexto cultural e de mercado quando da implantação da categoria Infantil Digital no Prêmio Jabuti, a relevância da premiação no mercado de livros do Brasil e as mudanças no regulamento da categoria ao longo dos anos - para

2 CONTE, Jaqueline.O livro digital interativo para crianças: Materialidade e evanescência - uma leitura a partir dos app-books vencedores do Prêmio Jabuti. 2019. 416 f. Dissertação (Mestrado em Estudos de Linguagens) - Universidade Tecnológica Federal do Paraná, Curitiba, 2019. Disponível em: http://repositorio.utfpr.edu.br/jspui/handle/1/4237. Acesso em: 18/05/2020.

3 Meu aplicativo de folclore, de Ricardo Azevedo (São Paulo: Ática, 2013); Via Láctea de Olavo Bilac, de Samira Almeida e Fernando Tangi (São Paulo: StoryMax, 2014); Flicts, de Ziraldo (São Paulo: Melhoramentos, 2014); Pequenos grandes contos de verdade, de Oamul Lu e Isabel Malzoni (Caixote, 2015); Mãos mágicas, de Tereza Yamashita e Suppa (SESI-SP, 2015); Chove chuva - Aprendendo com a natureza: sabedoria popular, de Magali Queiroz (Alis, 2015); Coleção Kidsbook Itaú Criança (Agência Africa, 2016); Nautilus - Baseado na obra original de Júlio Verne: Vinte mil léguas submarinas, de Maurício Boff (StoryMax, 2016); e Quanto bumbum!, de Isabel Malzoni (Caixote, 2016). 
focarmos na segunda parte, que traz à luz alguns gargalos dessa nova materialidade literária. Antes, porém, apenas alguns dados importantes, que mostram o panorama geral do mercado editorial do país nos últimos anos, cenário em que se inserem, timidamente, os livros digitais:

De 2006 a 2017, o faturamento da indústria editorial brasileira caiu 21\%. Considerando apenas o subsetor de Obras Gerais - do qual fazem parte, entre outros gêneros, os livros de literatura, inclusive infantis e juvenis - a queda chegou a 44\%. As livrarias, que em 2017 eram o principal canal de vendas das editoras brasileiras, respondendo por 53\% dos livros comercializados no mercado (não governamental), vêm acumulando dívidas e fechando, com quadro agravado a partir de 2013. Em dez anos, de 2007 a 2017, o país perdeu 21 mil livrarias e papelarias. Mesmo grandes grupos, como Saraiva, Cultura e Laselva, entraram em falência ou estão em recuperação judicial. Num mercado editorial em franco achatamento, onde mesmo as compras governamentais, antes altamente relevantes, sofreram cortes significativos, a leitura digital não se mostra como antídoto, sendo ainda incipiente.

A pesquisa Retratos da Leitura no Brasil, do Instituto Pró-Livro (2016), mostrou que, em um país onde já se lê pouco (4,9 livros, inteiros ou em parte, por habitante por ano), 59\% das pessoas nunca ouviram falar de livros digitais. O Censo do Livro Digital, realizado pela Fundação Instituto de Pesquisas Econômicas (FIPE/CBL/SNEL, 2017), mostrou que apenas 37\% das editoras produzem livros ditos digitais (em geral, versões digitais de livros impressos) ${ }^{4}$.

Nesse panorama da indústria editorial, já cruel para o consumo mesmo das formas tradicionais de livro e leitura, inserem-se os livros digitais com alto grau de interatividade, feitos para dispositivos móveis, uma nova materialidade que traz consigo, pari passu a possibilidades inovadoras, gargalos desafiadores. Trata-se de um formato ainda recente para a literatura infantil e juvenil, com apenas uma década de história. Vale lembrar que o iPad, primeiro suporte físico para o qual foram desenvolvidas essas produções, só apareceu em 2010. Neste mesmo ano é que foi lançado no Brasil o livro-aplicativo A menina do narizinho arrebitado, um dos livros infantis digitais de caráter interativo e hipermidiático pioneiros no país (LAJOLO, ZILBERMAN, 2017, p.18); era uma versão da obra clássica de mesmo título escrita por Monteiro Lobato, exclusiva para iPads, lançada pela editora Globo.

As produções literárias digitais interativas passaram a ganhar maior visibilidade no mercado com a criação - pela mais importante feira internacional do segmento de livros, a Feira do Livro de Bolonha, na Itália - do prêmio Bologna Ragazzi Digital Award, em 2012. Na esteira da experiência internacional, três anos depois, em 2015, o Prêmio Jabuti instituiu categoria similar, a denominada Infantil Digital, para reconhecer as produções nacionais. A experiência do prêmio brasileiro durou apenas três anos, depois que o número de inscritos caiu dramaticamente (de 38 obras, em 2015, para

4 Dados de diversas pesquisas (SNEL/CBL. Pesquisa Produção e Vendas do Setor Editorial Brasileiro - Série Histórica, 2018; estudo comparativo de dados da Relação Anual de Informações Sociais (RAIS), do Ministério do Trabalho, feito pela Confederação Nacional do Comércio de Bens, Serviços e Turismo (CNC), 2018; FIPE/CBL/SNEL. Censo do Livro Digital, 2017; Instituto Pró-Livro. Retratos da Leitura no Brasil, 2016), comentadas e referenciadas no item 3.5 da referida dissertação. 
16, no ano seguinte, e seis, em 2017), e após reformulação total no regulamento da $60^{\text {a }}$ edição do Jabuti, que fundiu ou extinguiu 11 das 29 categorias então existentes. Em 2018, o Prêmio passou a ter 18 categorias e a Infantil Digital foi descontinuada.

As novas possibilidades em termos estéticos e de propostas de leitura que trazem as produções literárias para dispositivos móveis -interativas, hipermidiáticase multilinguagens - tornam-nas muito mais complexas, comparando-se aos livros impressos tradicionais, e também mais caras de se produzir5. Animadores, designers de experiência do usuário (UX Designers) e desenvolvedores são alguns dos atores que ganham relevância na criação dessas obras, podendo mesmo vir a alterar, em discussões futuras, o próprio conceito de autoria de um livro. Todas essas expertises envolvidas encarecem a produção da obra, assim como ocorre com a necessidade de disponibilização permanente de profissional apto a realizar a manutenção e a atualização das produções. Isso para que todos os recursos utilizados permaneçam em perfeito funcionamento, ao longo dos anos, mesmo após as frequentes atualizações de sistemas feitas pelas empresas responsáveis pelos dispositivos em que esses livros são lidos (devices) e pelas lojas de venda on-line dos aplicativos.

Ao contrário da lógica do livro impresso - em que uma obra pode permanecer indefinidamente em uma biblioteca física, ainda que a editora responsável pela publicação deixe de existir -, no livro digital interativo, sobretudo quando se trata de um app-book, que é um software em si mesmo e não um simples arquivo, há dependência direta entre a obra e sua editora/produtora/mantenedora, e entre esta e as políticas das empresaspor meio das quais o produto é disponibilizado para download e leitura. Se o sistema iOS ou o Android é atualizado e essa atualização provoca mau funcionamento no livro, a editora ou agência responsável pela obra deve atualizá-lo, caso não queria que o livro deixe de funcionar ou mesmo que seja removido das lojas de venda.

Entre as 13 obras estudadas (nove vencedores, sendo oito livros e uma coleção), três já haviam desaparecido das "prateleiras virtuais", por falta de atualização, até julho de 2018: Meu aplicativo de folclore ( $1^{\circ}$ lugar no Jabuti em 2015, produzido pela EditoraÁtica, com textos e ilustrações de Ricardo Azevedo); Chove chuva - aprendendo com a natureza: sabedoria popular ( $3^{\circ}$ lugar em 2016 , da Editora Alis, com texto de Magali Queiroz, ilustrado por Gabi Moraes); e Flicts (3º lugar em 2015, Editora Melhoramentos/Engenhoca Filmes, com textos e ilustrações de Ziraldo). Esses app-books estiveram disponíveis para download nas lojas dos aplicativos dos sistemas iOS ou Android por um período de dois a cinco anos, apenas. Entre as obras vencedoras, só duas nunca haviam sofrido atualizações para adaptações, correção de erros e melhorias em geral, após serem disponibilizadas.

\footnotetext{
5 Segundo Marina Pastore, coordenadora de Livros Digitais da editora Companhia das Letras, o desenvolvimento do app-bookQuem soltou o PUM?, desenvolvido em 2011, custou em torno de R $\$ 20$ mil, sendo que a produção de um e-book em E-PUB de layout fixo, sem elementos interativos, do mesmo livro ficaria em torno de R\$500,00. (CONTE, 2019, p. 239). App-books como Pequenos grandes contos de verdade, da Editora Caixote, e Nautilus, desenvolvido pela empresa Storymax, ambos premiados em segundo lugar no Prêmio Jabuti, nos anos de 2017 e 2016, respectivamente, custaram mais de $\mathrm{R} \$ 30$ mil. Nautilus havia ganhado um edital de fomento de R\$50 mil, embora a editora não tenha recebido o recurso integral para sua execução.
} 
A exemplo do que ocorreu com os livros vencedores do Jabuti, outras obras de qualidade, tanto nacionais como internacionais, também não podem mais ser baixadas. É o caso de The Fantastic Flying Books of Morris Lessmore, escrito por William Joyce, produzido pela empresa americana Moonboot Studios e de Quem soltou o PUM?, de Blandina Franco (texto) e José Carlos Lollo (ilustrações), produzido pela Companhia das Letras. Este último, lançado em 2011 e descontinuado em 2018, foi finalista do Bologna Ragazzi Digital Award, em 2012, ano da primeira edição do prêmio. Explica Marina Pastore, coordenadora de Livros Digitais da editora:

Os três aplicativos [que haviam sido feitos pela Companhia das Letras] tiveram as vendas suspensas a partir de janeiro deste ano. Consideramos que eles já não forneciam uma experiência de leitura tão boa, já que acabamos não conseguindo investir nas atualizações necessárias para que os apps funcionassem bem nas versões mais recentes do iOS. (PASTORE, 2018, em entrevista por e-mail, apud CONTE, 2019, p. 149)

Assim, verificamos que a evanescência (ou obsolescência) é um grande problema enfrentado pelos produtores e pelos consumidores de livros digitais para crianças. Este fato influi até na viabilidade de mapeamentos e de estudos posteriores dessas obras por pesquisadores da literatura digital. Sinaliza, ainda, o que parece ser uma impossibilidade: a formação de cânones neste tipo de literatura.

Alamir Aquino Corrêa (2016) pontua bem essa dificuldade que a evanescência das obras digitais cria, quando aborda de forma geral a literatura em meio digital:

[...] alguns objetos podem ter perdido a possibilidade de sua execução, por não haver mais o suporte necessário para sua reapropriação (tanto em termos de software quanto em termos de hardware) ou, se há, o seu custo é por demais elevado. [...] Pesquisas sobre tais objetos não podem ser repetidas, dando aos estudiosos um poder inimaginável - o de uma confiabilidade pela inexistência dos objetos eventualmente eliminados por decisão corporativa, venda de softwares por companhias que preferem eliminá-los, desinteresse em razão de seu envelhecimento tecnológico ou mesmo fatos fortuitos, como a perda de direito de uso de domínios de sítios. É como se estivéssemos a lidar com civilizações ou culturas extintas - a construir uma teoria sobre o nada. Rastros desses materiais sugerem o nascimento de uma arqueologia cibernética a lidar com pedras deRosetta quase contemporâneas. (CORRÊA, 2016, p. 244) 
A pesquisa nesse meio, portanto, além de difícil, confere ainda maior responsabilidade ao pesquisador, uma vez que seus estudos podem ser tudo o que sobrará para se "conhecer" determinadas obras. E o que sobrará será sempre apenas uma vaga ideia daquilo que foi o objeto, uma vez que não é possível reproduzir, nos meios tradicionais de registro da pesquisa científica, a experiência de leitura, tal qual proposta, nem todos os recursos e linguagens que o livro utilizou.

A materialidade do livro digital interativo é, em si, complexa, e explicá-la já serve para sinalizar diversos aspectos que influem na experiência de leitura/consumo desses livros. No trabalho realizado, propusemos uma definição que traz em seu âmago a conhecida máxima de McLuhan: “o meio é a mensagem” (MACLUHAN, 2011, p. 21), uma vez que um e outro se confundem na materialidade do digital. A definição proposta também deriva da interpretação de reflexões trazidas pelas pesquisadoras Katherine N. Hayles (2002) e Ana Elisa Ribeiro (2017). Afirma Hayles, em seu livro (impresso) Writing Machines:

\begin{abstract}
Não estamos acostumados a pensar em um livro como uma metáfora material, mas, na verdade, ele é um artefato cujas propriedades físicas e usos históricos estruturam nossas interações com ele de maneiras óbvias e sutis. Além de definir a página como uma unidade de leitura, e vincular as páginas sequencialmente para indicar uma ordem de leitura, existem convenções menos óbvias, como a opacidade do papel, uma propriedade física que define a página como tendo dois lados com relação linear e sequencial, em vez de interpenetrante e simultânea. Mudar a forma física do artefato não é meramente mudar o ato de ler (embora isso também tenha consequências cuja importância estamos apenas começando a reconhecer), mas, profundamente, transformar a rede metafórica que estrutura a relação entre palavra e mundo." (HAYLES, 2002, p. 22 e 23, tradução nossa)
\end{abstract}

Aqui, Hayles nos chama a atenção para algo extremamente relevante. As propriedades físicas e a forma como usamos historicamente o que costumamos chamar de livro influem no exercício de dar significado às palavras e a outros componentes semiológicos, na nossa maneira de construir relações entre linguagem e realidade e, ao fim e ao cabo, de ler o mundo. Imaginemos: lemos um livro tradicional, em páginas numeradas sequencialmente; lemos um livro impresso que tem algumas folhas propositadamente unidas e temos que separá-las para prosseguir a leitura; lemos um livro de plástico; lemos um livro com folhas soltas; lemos um livro em que temos que clicar em links à nossa escolha para construirmos a história; lemos um livro que exige que chacoalhemos ou giremos o 
dispositivo para descobrirmos o restante do enredo, acompanhado por música que nos sugere o clima da história. A relação que criamos com o texto e, dele, com o mundo, modifica-se de acordo com a materialidade.

Da mesma forma, a materialidade diz muito sobre as relações culturais, sociais e políticas de uma sociedade, sobre nossa "rede socio técnica". Como nos lembra Ribeiro:

Os livros são existências, impressas ou digitais, autossuficientes como objeto ou, mais recentemente, dependentes de devices, que nos conectam uns aos outros, costuram relações e alteram sentidos na existência humana. Não basta pensá-los como se fossem secções de um mundo inanimado, como poderíamos, desde há muito tempo e um tanto inadvertidamente, descrevê-los. É preciso pensá-los como integrantes desta grande interação de que todos fazemos parte, já que os livros encapsulam nossas ideias, boas ou ruins, atuando como sinapses, quando lidos, relidos, discutidos, resenhados, mal falados, copiados, citados, colecionados, doados, queimados, reimpressos, esquecidos para serem relembrados. Não são híbridos de humano e objeto, mas são objetos de mobilização, interação e jogos de poder.

A materialidade dos livros traz implicações não apenas para sua própria forma de existir - em papel, tal ou qual, com lombada, orelhas, capas, ou digital, mostrado em um equipamento de dimensão X ou Y, tal ou qual capacidade de memória ou processamento, e assim... -, mas para nossa existência humana, profissional, social. (RIBEIRO, 2017, artigo on-line)

O que dizemos e como dizemos mostra muito do que somos, do nosso desenvolvimento tecnológico, de nossas ideias e aspirações, de nossas engrenagens socioeconômicas, de nossa cultura e relações políticas. Os livros e sua materialidade também nos contam muito sobre essas tramas, sendo “objetos de mobilização, interação e jogos de poder”(RIBEIRO, 2017).

Vejamos: o que nos diz um livro feito em altas tiragens, dotado de ficha de leitura, lançado por uma editora com dezenas de divulgadores, como eram as obras da série Vaga-Lume nos anos 1980, editada pela Ática? Um cadáver ouve rádio, de Marcos Rey, vendeu cerca de 140 mil exemplares só no semestre de lançamento. Podemos imaginar todo o ciclo econômico e social (e afetivo) desse livro e também o público-alvo a que se destinava: os leitores em ambiente escolar. E o que nos diz um livro-aplicativo desenvolvido em um formato proprietário para leitura exclusiva em um iPad? Quanto custa um iPad? Quantas e que perfil de pessoas têm um iPad? Quem poderá acessar esse livro? Que experiência de leitura esse usuário leitor terá? 
Assim, considerando a relação humana com as propriedades físicas do livro e a rede sociotécnica que perpassa a construção e o consumo desse objetos, propomos entender a materialidade do livro digital interativo como o fator gerador da experiência estética e humana resultante da soma de três elementos: o meio digital, o formato da obra e o dispositivo de leitura. Essas singularidades influirão diretamente na maneira como o leitor fruirá essa obra e na sua experiência de leitura. Em outras palavras, a materialidade do livro digital interativo é "a soma de recursos tecnológicos que envolvem o meio (digital), as técnicas de produção e os dispositivos para leitura" (CONTE, 2019, p. 156), como observamos na já referida dissertação:

O livro digital interativo, para além de seu conteúdo, é mais do que um meio (meio digital), mais do que o software em que é desenvolvido, e mais do que o aparelho em que é fruído (dispositivos/devices). Tais produções são multidependentes: se acessadas pela internet, por exemplo, dependem do meio digital e de suas conexões; se desenvolvidas com a utilização de um software, dependem da política de uso desse programa (se é aberto ou proprietário); se só podem ser lidas em um tipo de sistema operacional ou dispositivo, dependem do suporte, do equipamento de leitura. Todos esses aspectos influenciam na experiência do usuário leitor.

Tratam-se aqui de livros feitos para serem fruídos no meio digital. Imprimir suas telas, com textos e imagens estáticas, não traria a mesma experiência de leitura franqueada em dispositivos digitais, por exemplo. O meio é, portanto, um fator primordial. Da mesma forma, um e-book em formato EPUB exibido em um computador de mesa proporciona uma experiência de leitura diferente daquela obtida com um e-book lido em um leitor Kindle, por exemplo (que, inclusive, não é colorido), ou de um app-book cheio de interações acessado em um celular e ou tablet. Livros digitais podem ser produzidos em diferentes formatos, como apontado anteriormente (EPUB e app, por exemplo), sendo que cada qual pressupõe, na ponta, um ou mais equipamentos ou dispositivos de acesso que permitam sua efetiva leitura - a dimensão tangível de determinada produção editorial no momento de sua fruição. Programas, formatos e dispositivos são, portanto, fatores também fundamentais na construção da materialidade do livro digital interativo [...].(CONTE, 2019, p. 156)

Assim, para dar um exemplo, poderíamos afirmar que a materialidade do livro Pequenos grandes contos de verdade, de Isabel Malzoni e Oamul Lu, lançado pela Editora Caixote, em 2015, é a de um livro digital em formato de aplicativo, para leitura em dispositivos móveis do sistema iOS (iPads e iPhones). 
Tal materialidade possibilita a utilização de muitos recursos de interação e uma experiência de leitura diferenciada (no caso deste app-book, que ocupa 484 megabytes de memória, jogos integrados à animação, leitura e gravação da história com a própria voz do leitor, músicas, entre outros recursos). No entanto, só pode ser fruída por pessoas que tenham dispositivos móveis da marca Apple (e com memória suficiente), cuja aquisição está longe da realidade da maioria da população brasileira, estando as formas de venda/acesso ao livro submetidas às políticas de uma corporação e às suas estratégias de atualizações de sistema. Ou seja, a materialidade nos diz muito a respeito do livro como produto cultural, social e economicamente dirigido.

Não é de se negar, no entanto, que a possibilidade de se baixar um livro imediatamente, em qualquer lugar do país (ou do mundo), sem a necessidade de uma rede logística física, podendo chegar mesmo a locais que não têm livrarias ou bibliotecas, é uma vantagem importante das obras digitais. Isso é algo que não pode ser ignorado, mesmo que não signifique garantia de acesso, em função das condições socioeconômicas e culturais de grande parte da população brasileira e das escolas do país, que não contam necessariamente com dispositivos que permitam tal leitura.

Também não é de se negar o benefício de se poder oferecer, em uma mesma obra, opções de leitura e de narração em diferentes línguas, o que pode ampliar o público do livro para outros países, bem como ajudar na familiarização das crianças brasileiras com outros idiomas. Entre os nove vencedoresdo Jabuti analisados em nossos estudos, seis são livros apenas em português, um é bilíngue (português e inglês) e dois trilíngues (português, espanhol e inglês).

É de ressaltar, ainda, as vantagens de algumas dessas obras na inclusão literária de pessoas cegas, por exemplo, à medida que tenham narrações orais integradas. Dos livros analisados, apenas a Coleção Kidsbook Itaú Criança não tinha a opção de narração oral ${ }^{6}$.

Nesse universo de vantagens e dificuldades da literatura infantil em meio digital, observa-se um outro movimento: o das bibliotecas digitais, que aos poucos vão expandindo seu público, oferecendo obras literárias que podem ser lidas em computadores de mesa e dispositivos móveis, dentro e fora da escola. A maior parte das obras disponibilizadas por essas bibliotecas são em formato E-PUB - com interações mais restritas queas dosapp-books. Algumas empresas disponibilizam obras ainda mais simples, em arquivos PDF, não interativos - que hoje não consideramos como livro digital, mas como obra digitalizada.

Entre essas bibliotecas digitais estão as plataformas Árvore de Livros e Elefante Letrado, ambas criadas em 2014, que oferecem, além do acesso a uma vasta gama de títulos, relatórios de leitura e assessoria pedagógica. A primeira contava, em maio de 2018, com mais de 10 mil livros, de

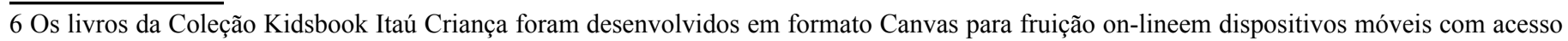
à rede social Facebook. 
180 editoras, no acervo, tendo como clientes 200 escolas, com foco nas particulares. Naquele ano, 85\% dos livros do acervo da Árvore eram em E-PUB.Em 2019, a Árvore de Livros fundiu-se com a plataforma gamificada de leitura de atualidades Guten, formando a Árvore Educação. De acordo com reportagem publicada em setembro de 2019, a empresa já atenderia 200 mil alunos de 500 escolas brasileiras, com 30 mil títulos de 600 editoras (PUBLISHNEWS, 2019).

A Elefante Letrado, que começou a funcionar efetivamente em 2015, oferecia, também em 2018, 540 livros em português e 430 em inglês, atendendo 115 escolas e 20 mil estudantes, com foco no ensino fundamental I (crianças de 6 a 11 anos). Todas as obras do acervo eram disponibilizadas em E-PUB 3, de layout fixo. Em maio de 2020, a empresa contava com 186 escolas e 35.784 alunos atendidos, com uma média de 13 mil livros lidos diariamente (contagem realizada por um algoritmo que leva em consideração o livro em leitura e o tempo médio de leitura de uma criança, de acordo com o ano escolar). O acervo contava com 580 livros em português e a mesma quantidade de obras em inglês.

De acordo com a diretora-executiva da empresa, Mônica Timm de Carvalho,a ideia da empresa não é ter um conjunto muito grande de livros, "porque nenhuma criança vai ler 5 mil, 10 mil livros ao longo dos cinco anos do ensino fundamental 1" (CARVALHO, 2020, por e-mail). Ela explica a lógica do trabalho:

A nossa proposta é apresentar um conjunto factível de livros para a leitura das crianças, livros esses que perfaçam em torno de 20 gêneros textuais diferentes e estejam nivelados pela proficiência dos leitores, de primeiro ao quinto ano do Ensino Fundamental. É muito mais uma seleção bem pensada para transformar estudantes em crianças letradas, do que um ambiente que apenas contenha acervo em uma biblioteca digital. Para tanto, nós desenvolvemos uma arquitetura pedagógica que visa a apoiar o desenvolvimento do hábito da leitura e a desenvolver a compreensão leitora. De uns tempos pra cá, investimos ainda mais no aprimoramento dos jogos de perguntas, todos eles alinhados à BNCC - Base Nacional Comum Curricular, os quais trabalham com as três grandes habilidades de leitura: a identificação de informações explícitas no texto; o estabelecimento de relações entre partes do texto e, por último, a mais complexa, a da formulação de inferências a partir do que está escrito no texto. Como eu sempre gosto de repetir: aprender a ler as linhas, as entrelinhas e o que há por detrás das linhas. (CARVALHO, 2020, por e-mail).

Percebemos aqui a preocupação das bibliotecas digitais não apenas na difusão da literatura 
para a infância, mas no apoio didático às escolas, posicionando-se, ainda, como ferramenta para o letramento literário digital. Esse é um novo modelo de negócio que o universo do livro digital propiciou.

No breve percurso deste artigo, pudemos observar a complexidade do livro digital interativo, com seus diversos formatos e custos; múltiplos autores e expertises envolvidas; dependência de grandes players do mercado (responsáveis pelos dispositivos de leitura e lojas de vendas); insegurança quanto à "vida útil" da obra (em função da evanescência tecnológica); acesso do público aos dispositivos de leitura. Também pudemos observar como algumas empresas se posicionam com modelos de negócio voltados às escolas e ao apoio didático.

Todas as questões levantadasem relação a essa nova materialidade do livro e da literatura para a infância desafiam o mercado, as escolas e os entusiastas da literatura digital interativa, e ajudam a explicar porque caminhamos ainda em passos lentos diante de um recurso tão fascinante em termos de possibilidades estéticas.

\section{Referências}

CONTE,Jaqueline.O livro digital interativo para crianças: Materialidade e evanescência - uma leitura a partir dos appbooks vencedores do Prêmio Jabuti. 2019. 416 f. Dissertação (Mestrado em Estudos de Linguagens) - Universidade Tecnológica Federal do Paraná, Curitiba, 2019. Disponível em: http://repositorio.utfpr.edu.br/jspui/handle/1/4237. Acesso em: 18 maio 2020.

CARVALHO, Mônica Timm, Entrevista concedida a CONTE, por e-mail, 22 maio 2020.

CORRÊA, Alamir Aquino. Portabilidade, evanescências e rubricas: discussões em torno da literatura digital na sala de aula. In:MATLIT: Materialidades da Literatura, [S.1.], v. 4, n. 2, p. 233-253, jul. 2016. ISSN 2182-8830. Disponível em: https://impactum-journals.uc.pt/matlit/article/view/2182-8830_4-2_11. Acesso em: 21 maio 2020.

HAYLES, N. Katherine. Writing machines. Cambridge, Mass.: MIT Press, Mediaworks Pamphlet Series, 2002. 144 p.

LAJOLO, Marisa; ZILBERMAN, Regina. Literatura infantil brasileira: uma nova/ outra história. Curitiba: PUCPress, 2017. 
MCLUHAN, Marshall. Os meios de comunicação como extensões do homem. Trad. Décio Pignatari. São Paulo: Cultrix, 2011 [1964].

PUBLISHNEWS. Árvore de Livros cresce e viraÁrvoreEducação. 30 set. 2019. Disponível em: https://www. publishnews.com.br/materias/2019/09/30/arvore-de-livros-cresce-e-vira-arvore-educacao. Acesso em: 22 maio 2020.

RIBEIRO, Ana Elisa. O bibliógrafo digital: questões sobre a materialidade do livro no século XXI. In: Perspectivas em Ciências da Informação. Belo Horizonte, v. 22, n. spe, p. 120-130, jul. 2017. Disponível emhttps://www.scielo.br/ scielo.php?pid=S1413-99362017000600120\&script=sci_arttext. Acesso em: 21 maio 2020. 